\title{
Circadian Disruption, Sleep Loss, and Low-Grade Inflammation
}

\author{
Rüdiger Hardeland* \\ University of Göttingen, Germany
}

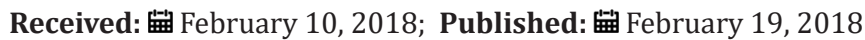

*Corresponding author: Rüdiger Hardeland, Johann Friedrich Blumenbach Institute of Zoology and Anthropology, University of Göttingen, Bürgerstr. 50, D-37073 Göttingen, Germany

Abbreviations: SCN: suprachiasmatic nucleus; CRP: C-reactive protein; SASP: senescence-associated secretory phenotype; DDR : DNA damage response; AD: Alzheimer's disease

\section{Editorial}

Circadian rhythmicity is a fundamental property of the majority of organisms, including bacteria, unicellular eukaryotes, fungi, plants and animals. It is generated by cellular oscillators and may have evolved to cope with adverse phases in the cycle of a day that bear the risk of damage by radiation and reactive metabolites, such as free radicals. In a complex organism like the human, the circadian system is composed of numerous, internally communicating, oscillators including a coordinating master clock, the suprachiasmatic nucleus (SCN) [1]. It provides a program for structuring countless physiological functions in a sophisticated temporal pattern that optimizes the alignment of processes and also the anticipation of regularly expectable changes, such as an approaching time of arousal and locomotor activity, of food intake and even social interactions.

Sleep is one of the functions that are controlled by the circadian system, in addition to the homeostatic drive to sleep and immunological influences. The benefits of sleep concern recovery, but additionally other processes such as memory consolidation take place in specific sleep phases [2]. Shift work and on-call duties during night are necessities in our modern world. Many scientists also know what it means to conduct an experiment that lasts for, e.g., 35 hours, without any chance to sleep in between. The consequence to the body is, however, not just subsequent fatigue, but also a disturbance of the finely tuned physiological rhythms. The resilience of individuals to such disturbances is highly variable. Not rarely, subjects also wake throughout the night for private reasons.

Although this shall not be generally criticized, one should know how many changes are induced by sleep loss, with the potential of pathophysiological alterations that should not accumulate to avoid disorders and diseases. Sleep deprivation is frequently associated with disruptions or inappropriate phase shifts of the circadian system, also known under the term of chronodisruption. In humans, one typical reason of the dual changes results from light exposure at night. This can induce phase shifts of circadian rhythms, but also involves another complication, as light at night causes rapid decreases in the levels of the pineal hormone, melatonin, known as the so-called photic shutoff, in addition to the circadian changes [3]. These reductions in melatonin are in multiple ways undesired. First, melatonin is a highly pleiotropic regulator molecule that orchestrates countless functions in all organs of the body [4].

Second, melatonin participates in the entrainment of the master clock and various peripheral oscillators [5]. Third, melatonin is a neuro protective, antiapoptotic and antioxidant agent, with additional functions in immune modulation $[4,6]$. Low-grade inflammation is of particular relevance in immunosenescence, in aging acceleration and in neurodegenerative disorders, but contributes to many other pathologies. Immunosenescence can lead, in addition to other traits, to the development of a proinflammatory phenotype characterized by elevated proinflammatory cytokines and C-reactive protein (CRP), especially in subjects that have acquired an immune risk profile [7]. Moreover, the age-dependent increase in DNA-damaged cells represents a further source of proinflammatory factors via the senescence-associated secretory phenotype (SASP).

SASP, being part of the DNA damage response (DDR), allows non-immune cells to release proinflammatory cytokines and chemokines which spread inflammatory responses [8,9]. In 
the central nervous system, astrocytes with SASP can become neurotoxic [10]. Another brain-related aspect concerns neuronal overexcitation, which results via NO release in microglia activation and astrogliosis, followed in vicious cycles by mutual stimulations between the three cell types $[7,11]$. Moreover, the balance between formation and clearance of amyloid- $\beta$ (A $\beta$ ) peptides and oligomers, which are both prooxidant and proinflammatory, can be disturbed. This is not exclusively a matter of Alzheimer's disease (AD), but rather plays - at lower level - a role in normal aging, too. Finally, insulin resistance in the brain has been identified as an early sign and, presumably, stimulus of neuro inflammation in AD [7,12-14], a potentially important link to the inflammatory aspect of type 2 diabetes and metabolic syndrome.

Sleep deprivation, often in conjunction with circadian disruption, can favor in multiple ways processes that are known to be related to low-grade inflammation. Apart from various reports that demonstrated oxidative stress as a result of primary insomnia or experimental sleep deprivation, which shall not be discussed here in detail, direct evidence for increased inflammation has been obtained in clinical and preclinical studies. In humans, sleep deprivation or disturbance elevated TNF- $\alpha[15,16]$ and IL-6 in monocytes $[16,17]$, CRP $[17,18]$, TNF- $\alpha[18,19]$ and IL-6 $[20,21]$ in the plasma. In whole blood preparations, mRNA levels of TNF- $\alpha$ and of its soluble receptor sTNFR1 were reported to be enhanced [22]. Moreover, sleep deprivation was shown to induce DDR and SASP in elderly subjects [23]. Of course, studies in humans have limitations concerning the availability of tissue material. Moreover, blood analyses revealed a certain degree of divergence with regard to the increases in specific inflammatory markers [24]. However, the basis for judgments is considerably broader in laboratory rodents.

In the murine brain, sleep deprivation enhanced the proinflammatory cytokine TNF- $\alpha$, and the NO metabolite nitrite, in addition to indicators of oxidative stress [25]. Up regulation of TNF- $\alpha$, IL$1 \beta$ and IL- 6 was observed in numerous rat organs, such as adipose tissue, colonic mucosa, liver and spleen, sometimes also rises in IL-17 and IFN $\gamma$ (details not cited). More importantly, respective changes were observed in brain regions. Increases of IL-6 and IL-8 were demonstrated in the hippocampus [26-28], and of IL-6 in the cortex $[28,29]$. Moreover, anti-inflammatory cytokines, IL-4, and IL10 , were found to be decreased in the hippocampus $[26,27]$. While data on the important proinflammatory cytokine IL-1 $\beta$ were rather divergent in humans, the situation is rather unambiguous in rats and mice. It was enhanced in the hippocampus [26-31], cortex [2932], basal forebrain [30], and hypothalamus [31]

Finally, findings of utmost interest were detected upon sleep deprivation [33] or slow wave sleep disruption [34] in the CSF of healthy humans, in which the levels of $A \beta_{1-42}$ or $A \beta_{1-40}$, respectively, were increased, perhaps a sign of reduced $A \beta$ clearance. With regard to the proinflammatory properties of $A \beta$ peptides and oligomers, these results provide another hint for the role of sleep disturbanc- es in inflammation and, in older subjects, in brain inflammaging. Collectively, results summarized in this editorial emphasize the importance of inflammatory responses to sleep deprivation and disturbances. These may not be generally avoidable during professional life, but they should not be enhanced by lifestyle and can be prevented later in life, when these effects become more relevant and increasingly contribute to inflammaging.

\section{References}

1. Hardeland R (2017) Melatonin and the pathologies of weakened or dysregulated circadian oscillators. Journal of Pineal Research 62(1): e12377.

2. Ackermann S, Rasch B (2014) Differential effects of non-REM and REM sleep on memory consolidation? Current Neurology and Neuroscience Reports 14(2): 430.

3. Bonmati Carrion MA, Arguelles Prieto R, Martinez Madrid MJ, Reiter R, Hardeland R, et al. (2014) Protecting the melatonin rhythm through circadian healthy light exposure. International Journal of Molecular Sciences 15(12): 23448-23500.

4. Hardeland R, Cardinali DP, Srinivasan V, Spence DW, Brown GM, et al. (2011) Melatonin- A pleiotropic, orchestrating regulator molecule. Progress in Neurobiology 93: 350-384.

5. Hardeland R, Madrid JA, Tan DX, Reiter RJ (2012) Melatonin, the circadian multioscillator system and health: the need for detailed analyses of peripheral melatonin signaling. Journal of Pineal Research 52(2): 139-166.

6. Hardeland R (2005) Antioxidative protection by melatonin - Multiplicity of mechanisms from radical detoxification to radical avoidance. Endocrine 27(2): 119-130.

7. Hardeland R, Cardinali DP, Brown GM, Pandi Perumal SR (2015) Melatonin and brain inflammaging. Progress in Neurobiology 127-128: 46-63.

8. Young ARJ, Narita M (2009) SASP reflects senescence. EMBO Report 10(3): 228-230.

9. Coppé JP, Desprez PY, Krtolica A, Campisi J (2010) The senescenceassociated secretory phenotype: the dark side of tumor suppression. Annual Review of Pathology 5: 99-118.

10. Turnquist C, Horikawa I, Foran E, Major EO, Vojtesek B, et al. (2016) p53 isoforms regulate astrocyte-mediated neuroprotection and neurodegeneration. Cell Death and Differentiation 23(9): 1515-1528.

11.Hardeland R (2017) Melatonin and neuroinflammation: Encouraging findings vs. fundamental problems. In: Pineal Gland: Research Advances and Clinical Challenges (Català A, ed.), Nova Science, Hauppauge, pp 163-204.

12. Clark IA, Vissel B (2013) Treatment implications of the altered cytokineinsulin axis in neurodegenerative disease. Biochemical Pharmacology 86(7): 862-871.

13. De Felice FG, Lourenco MV, Ferreira ST (2014) How does brain insulin resistance develop in Alzheimer's disease? Alzheimer's \& Dementia: Journal of the Alzheimer's Association 10 Suppl 1: S26-S32.

14. Ferreira ST, Clarke JR, Bomfim TR, De Felice FG (2014) Inflammation, defective insulin signaling, and neurological dysfunction in Alzheimer's disease. Alzheimer's \&Dementia: Journal of the Alzheimer's Association 10 Suppl 1: S76-S83.

15. Carroll JE, Carrillo C, Olmstead R, Witarama T, Breen EC, et al. (2015) Sleep deprivation and divergent toll-like receptor-4 activation of cellular inflammation in aging. Sleep 38(2): 205-211. 
16. Irwin MR, Witarama T, Caudill M, Olmstead R, Breen EC, et al. (2015) Sleep loss activates cellular inflammation and signal transducer and activator of transcription (STAT) family proteins in humans. Brain Behavior and Immunity 47: 86-92.

17. Irwin MR, Olmstead R, Carroll JE (2016) Sleep disturbance, sleep duration, and inflammation: A systematic review and meta-analysis of cohort studies and sxperimental sleep deprivation. Biological Psychiatry 80(1): 40-52.

18. Wright KP, Drake AL, Frey DJ, Fleshner M, Desouza CA, et al. (2015) Influence of sleep deprivation and circadian misalignment on cortisol, inflammatory markers, and cytokine balance. Brain Behavior and Immunity 47: 24-34.

19. Chennaoui M, Sauvet F, Drogou C, Van Beers P, Langrume C, et al. (2011) Effect of one night of sleep loss on changes in tumor necrosis factor alpha (TNF- $\alpha$ ) levels in healthy men. Cytokine 56(2): 318-324.

20. Vgontzas AN, Zoumakis E, Bixler EO, Lin HM, Follett H, et al. (2004) Adverse effects of modest sleep restriction on sleepiness, performance, and inflammatory cytokines. Journal of Clinical Endocrinology and Metabolism 89(5): 2119-2126.

21. Haack M, Sanchez E, Mullington JM (2007) Elevated inflammatory markers in response to prolonged sleep restriction are associated with increased pain experience in healthy volunteers. Sleep 30(9): 11451152.

22. Chennaoui M, Drogou C, SauvetF, Gomez Merino D, Scofield DE, et al. (2014) Effect of acute sleep deprivation and recovery on Insulin-like Growth Factor-I responses and inflammatory gene expression in healthy men. European Cytokine Network 25(3): 52-57.

23. Carroll JE, Cole SW, Seeman TE, Breen EC, Witarama T, et al. (2016) Partial sleep deprivation activates the DNA damage response (DDR) and the senescence-associated secretory phenotype (SASP) in aged adult humans. Brain Behavior and Immunity 51: 223-229.

24. Mullington JM, Simpson NS, Meier Ewert HK, Haack M (2010) Sleep loss and inflammation. Best Practice \& Research Clinical Endocrinology \&Metabolism 24(5): 775-784.

25. Chanana P, Kumar A (2016) Possible involvement of nitric oxide modulatory mechanisms in the neuroprotective effect of Centellaasiatica against sleep deprivation induced anxiety like behaviour, oxidative damage and neuroinflammation. Phytotherapy Research 30(4): 671680 .

26. Wadhwa M, Kumari P, Chauhan G, Roy K, Alam S, et al. (2017) Sleep deprivation induces spatial memory impairment by altered hippocampus neuroinflammatory responses and glial cells activation in rats. Journal of Neuroimmunology 312: 38-48.

27. Wadhwa M, PrabhakarA, Ray K, Roy K, Kumari P, et al. (2017) Inhibiting the microglia activation improves the spatial memory and adult neurogenesis in rat hippocampus during $48 \mathrm{~h}$ of sleep deprivation. Journal of Neuroinflammation 14(1): 222.

28. Kaur T, Singh H, Mishra R, Manchanda S, Gupta M, et al. (2017) Withania somnifera as a potential anxiolytic and immunomodulatory agent in acute sleep deprived female Wistar rats. Molecular and Cellular Biochemistry 427(1-2): 91-101.

29. Chennaoui M, Gomez Merino D, Drogou C, Geoffroy H, Dispersyn G, et al. (2015) Effects of exercise on brain and peripheral inflammatory biomarkers induced by total sleep deprivation in rats. Journal of Inflammation (London) 12: 56.

30. Zielinski MR, Kim Y, Karpova SA, McCarley RW, Strecker RE, et al. (2014) Chronic sleep restriction elevates brain interleukin-1 beta and tumor necrosis factor-alpha and attenuates brain-derived neurotrophic factor expression. Neuroscience Letters 580: 27-31.

31. Ashley NT, Sams DW, Brown AC, Dumaine JE (2016) Novel environment influences the effect of paradoxical sleep deprivation upon brain and peripheral cytokine gene expression. Neuroscience Letters 615: 55-59.

32. Zielinski MR, Gerashchenko D, Karpova SA, Konanki V, McCarley RW, et al. (2017) The NLRP3 inflammasome modulates sleep and NREM sleep delta power induced by spontaneous wakefulness, sleep deprivation and lipopolysaccharide. Brain Behavior and Immunity 62: 137-150.

33. Ooms S, Overeem S, Besse K, Rikkert MO, Verbeek M, et al. (2014) Effect of 1 night of total sleep deprivation on cerebrospinal fluid $\beta$-amyloid 42 in healthy middle-aged men: a randomized clinical trial. JAMA Neurology 71(8): 971-977.

34. Ju YS, Ooms SJ, Sutphen C, Macauley SL, Zangrilli MA, et al. (2017) Slow wave sleep disruption increases cerebrospinal fluid amyloid- $\beta$ levels. Brain 140(8): 2104-2111.

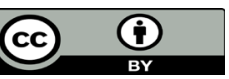

This work is licensed under Creative Commons Attribution 4.0 License

To Submit Your Article Click Here : Submit Article

DOI: $10.32474 /$ RRHOAJ.2018.01.000109

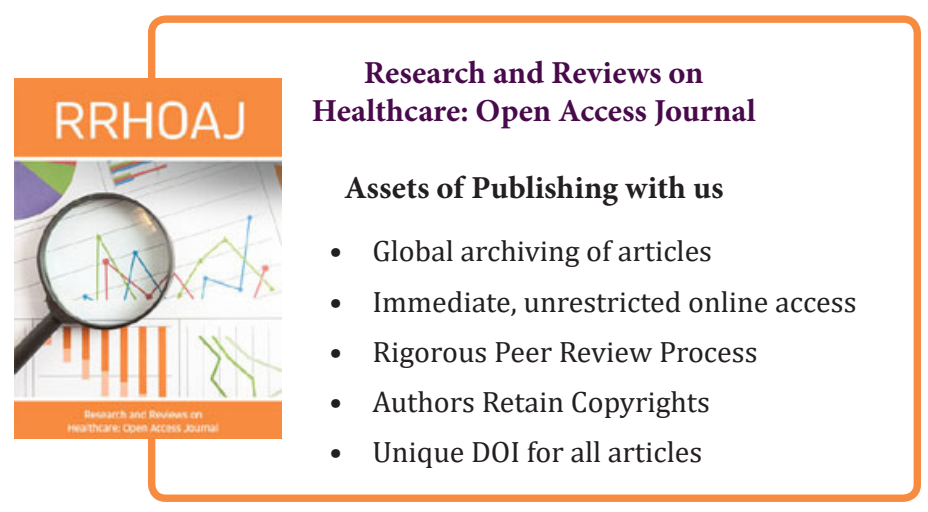

